\title{
THE ECOSYSTEM FOR ACCESSING TV SERIES AND FILMS IN SPAIN: AN OUTLINE OF THE SITUATION FOLLOWING THE INTELLECTUAL PROPERTY ACT 2015
}

\author{
El ecosistema para acceder a series de televisión y \\ películas en España: un esbozo de la situación a raíz \\ de la Ley de propiedad intelectual 2015
}

Carlos Aguilar-Paredes, Mario Pérez-Montoro, and Lydia Sánchez-Gómez

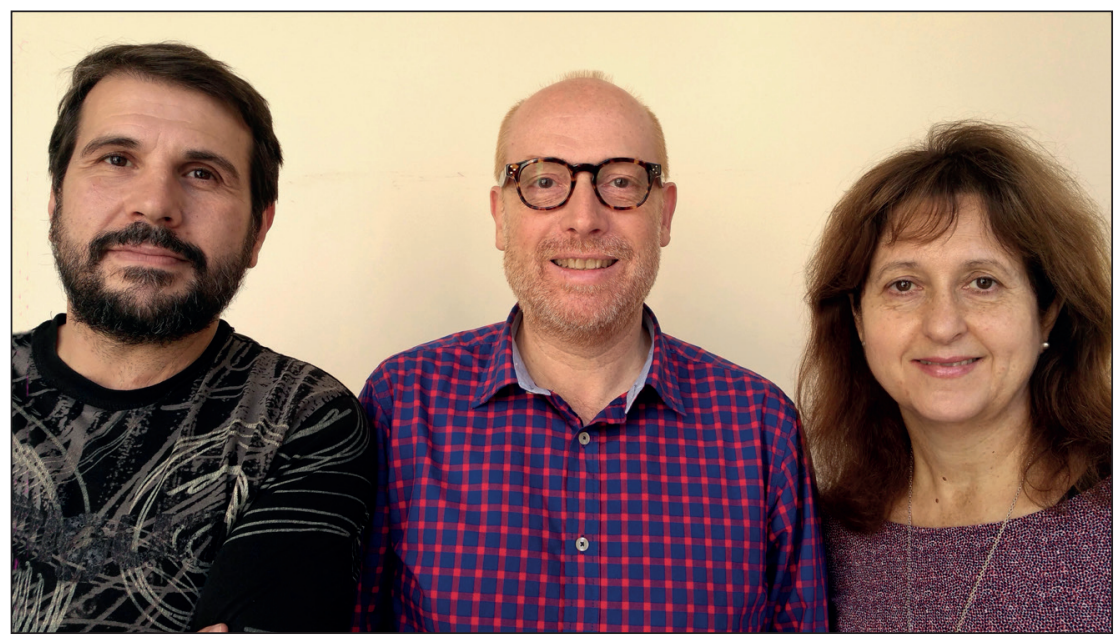

Carlos Aguilar-Paredes holds a PhD in Communication from the University of Barcelona (Spain). He is a lecturer in the Department of Information Science and Media Studies at the University of Barcelona (Spain). His research focuses on quantitative and qualitative methods applied to the analysis of media content. He also works on active audiences.

http://orcid.org/0000-0002-2165-4279

carlos.aguilar@ub.edu

Mario Pérez-Montoro holds a PhD in Philosophy and Education from the University of Barcelona (Spain) and a Master in Information Management and Systems from the Polytechnic University of Catalonia (Spain). He has been a visiting scholar at the Center for the Study of Language and Information (CSLI) at Stanford University (California, USA) and at the School of Information at UC Berkeley (California, USA). He is an associate professor in the Department of Information Science and Media Studies at the University of Barcelona (Spain) and director of the PhD Program in Information and Communication at this University.

http://orcid.org/0000-0003-2426-8119

perez-montoro@ub.edu

Lydia Sánchez-Gómez holds a PhD in Philosophy from Stanford University (California, USA). She is an associate professor in the Department of Information Science and Media Studies at the University of Barcelona (Spain). Her research focuses on communication theory, political communication, and the democratic quality of media.

http://orcid.org/0000-0001-7814-0087

Isanchezg@ub.edu

Universitat de Barcelona, Facultat de Biblioteconomia i Documentació Melcior de Palau, 140. 08014 Barcelona, Spain

\begin{abstract}
The widespread introduction of broadband Internet has transformed the traditional way of watching TV series and films. Beyond the legal services there is a widely established ecosystem that provides unauthorized access to copyrighted material; an ecosystem which, in Spain, represents a parallel channel on which to view content. We have analyzed the leading link provider websites in Spain over a period of one year, since enforcement on January 1, 2015 of the Revised Text of the Intellectual property act (Trlpi). Our analysis reveals how the ecosystem has been reorganized and its balance altered. However, in contrast to the objective of the measures proposed by the Trlpi, the new legislation has not led to a reduction in the size of the piracy ecosystem in Spain.
\end{abstract}

\section{Keywords}

Piracy; Audiences; Downloads; Streaming; Links website; Natural experiment; Spanish Intellectual property act. 


\section{Resumen}

La introducción generalizada de Internet de banda ancha ha transformado la forma tradicional de ver series de TV y películas. Más allá de los servicios legales hay un ecosistema ampliamente establecido que permite el acceso no autorizado a material con copyright; un ecosistema que en España representa un canal paralelo de consumo de contenidos. Hemos analizado los sitios web de los principales proveedores de enlaces en España durante un año, a partir de la entrada en vigor el 1 de enero 2015 del Texto Refundido de la Ley de propiedad intelectual (Trlpi). Nuestro análisis revela cómo el ecosistema ha alterado el equilibrio de este ecosistema y finamente se ha reorganizado. Sin embargo, en contraste con el objetivo de las medidas propuestas por la Trlpi, la nueva legislación no ha conducido a una reducción en el tamaño del ecosistema de la piratería en España.

\section{Palabras clave}

Piratería; Audiencias; Webs de enlaces; Descargas; Experimento natural; Ley de propiedad intelectual.

Aguilar-Paredes, Carlos; Pérez-Montoro, Mario; Sánchez-Gómez, Lydia (2016). "The ecosystem for accessing TV series and films in Spain: An outline of the situation following the Intellectual property act 2015". El profesional de la información, v. 25, n. 6, pp. 870-881.

https://doi.org/10.3145/epi.2016.nov.04

\section{Introduction}

Since their emergence, the cinema and then television have shaped our contemporary culture enormously. First in the cinemas and then in the privacy of our homes, the consumption of audiovisual content has become one of the main leisure activities in our society. Currently, the widespread introduction of broadband Internet has changed consumer habits and the market associated with distributing such material. The opportunity to see content outside broadcast schedules or specific physical places has shattered all existing patterns in the behavior of consumers of audiovisual media. A similar change is found locally: downloading and viewing TV series and films on the Internet has become firmly rooted in Spanish social and leisure activities (Jiménez; Martí; Palao, 2014).

The consumption of this kind of content has been regulated in Spain since early 2015 by a series of legal changes. Approval of the Revised intellectual property act (Trlpi) led to the introduction of a new measure: penalizing websites that provide access to illegal download links, in a modification of Article 158 (Spain, 2014):

"The procedure to re-establish legality is directed against the information society service providers who violate copyright laws, in the way referred to in the previous paragraph, by providing the description or location of works and other protected subject matter without evidence of permission. Thus, such providers undertake an active, non-neutral task that is not limited to merely acting as a technical intermediary. In particular, this includes all providers of ordered, classified lists of links to the works and other protected subject-matter referred to above, regardless of whether the links are initially provided by the intended recipients of the service."

The effect of the legislative and judicial measures on access to legally infringing content and the impact of these measures on the audiovisual content industry are active, although relatively recent, areas of study (Alcock; Nelson, 2012; Gavaldà-Miralles et al., 2014; Danaher; Smith, 2014; Marx, 2013; Khattak et al., 2014; Poort et al., 2014).
The results of these studies tend to correlate with the introduction of disruptive measures with the short- and mediumterm development of legal content consumption. Other studies have examined the change in traffic volume in P2P networks or changes in traffic type that occur by analyzing network packets (García-Dorado et al., 2012). In addition, variations in the penetration of illegal content consumption have been studied using a series of surveys of population samples, or a combination of the described methods (Poort et al., 2014).

The Revised Text of the LPI seeks to reduce illegal consumption of audiovisual content

The penalization of hosting links to legally infringing content that came into enforcement on January 1, 2015 almost coincided with the Swedish authorities shutting down Thepiratebay.se (TPB) website, and with legal action taken against the administrators of one of the main actors in the ecosystem, Seriespepito.com (SP). In Spain, the combination of all these factors had an impact on the piracy ecosystem comparable to the taking down of Megaupload in 2012. These actions created a situation in which a natural experiment (an empirical study in which the experimental conditions are determined by nature or by other factors outside the researchers' control) could be undertaken, such as those carried out by Danaher \& Smith (2013) and Adermon \& Liang (2014) on Megaupload and TPB.

\section{Objectives}

The Revised Text of the LPI seeks to reduce illegal consumption of audiovisual content and provide a solid legal framework that enables operators who legitimately offer access to such content to work in conditions of legal certainty (Trlpi: 23).

"The following set of measures is intended to improve the effectiveness of legal mechanisms aimed at protecting intellectual property rights against infringements 
they may suffer in the digital environment, which will undoubtedly result in an increased visibility of the legal offer of content in that environment and the fostering of new business models on the Internet."

The main aim of this article is to determine, in the context of this natural experiment, the impact of the new Trlpi on the ecosystem (the websites that offer unlicensed access to TV series and films) and, by extension, whether it may be established that the application of this policy has led to a transfer of users to providers of legal access to content.

Given the nature of the disruptive measure imposed by the Trlpi, in order to achieve the aim, it is necessary to break down and analyze the evolution of users' TV series and film consumption habits throughout 2015 in two different areas.

a) Access to illegal content in Spain through links on websites before and after application of the Trlpi.

b) The evolution of legal access of content throughout the study period. As the options of such access have changed during this time frame it will be necessary to break down the study of this market into two parts:

b.1) That of legal content access via over-the-top (OTT) services ${ }^{1}$.

b.2) Access via subscription to pay-TV and video-ondemand (VoD) services (both transactional - TVoD, and subscription - SVoD) that offer access to TV series and films in Spain.

Through analysis of the above data and contextualization of the legal content access market we will establish whether the new legislative initiative has driven users of infringing content to transfer to services providing legal material.

\section{Method}

\subsection{Study of the piracy ecosystem}

It is not easy to determine the ecosystem of websites that allow users to search for, download, and view films and TV series on the Internet. The analysis of this ecosystem as a whole (Price, 2013) or an examination of the elements comprising it (Zhang et al., 2011; Antoniades; Markatos; Dovrolis, 2009; Marx, 2013) has been the subject of numerous studies in specialized bibliographies, with a range of methodological approaches.

Some studies are based on an analysis of data on user traffic, classification by protocols and identification of the services that the data represent (Sanjuàs; Barlet-Ros; Solé-Pareta, 2012; García-Dorado et al., 2012).

User surveys are another method employed for studying the operation of these websites and their associated consumption patterns. The technique is commonly used by institutions in Spain to provide official figures on illegal consumption of content (Jiménez; Martí; Palao, 2014), as well as by administrators of download sites (Series.ly, 2014) to justify how well-established these practices are in society.

A third way of exploring consumption habits is by monitoring individual behavior in a sample of users, generally through the use of browser plug-ins. Such studies provide accurate data on the consumption habits of the sample group, which can then be extrapolated to the entire population. The main problem with the results is that they are always influenced by the suitability of the sample, which tends to be biased by specific characteristics of the users (only active consumers) who participate in the study (Gavaldà-Miralles et al., 2014).

All the aforementioned methods provide data that can be used to quantify the relative importance of different actors in the piracy ecosystem with varying degrees of accuracy, either because of the issues inherent in extrapolating results obtained using biased samples (data drawn exclusively from notable users), or because it is difficult to define behavior using small samples of traffic data.

As the measures introduced by the Trlpi were aimed at penalizing those websites that offer links to infringing content, our strategy focuses on analyzing the evolution of access with origin in Spain to such sites throughout 2015.

The main aim of this article is to determine the impact of the new Trlpi

Since no specific studies have been designed to obtain traffic data, specialized companies such as Alexa.com, Similarweb. com, and SenRush.com provide estimates of the number of users and pages visited. These companies give an overview of traffic, based on data obtained using a combination of existing methods: panels in users' browsers, search engine relevance, and user surveys.

http://www.alexa.com/about

Using data obtained from Alexa.com, we quantified the ecosystem that comprised the most popular link websites in Spain before and after the application of this combination of constraining judicial and legislative actions.

To conduct our study we began by identifying the main websites that are used in Spain to access links to unauthorized audiovisual content, either for direct viewing by streaming (using the link to an $\mathrm{OCH}^{2}$ service or through the inclusion of embedded video), direct file downloads, or downloads via P2P networks.

The sites included in the study were obtained from four sources:

- First, we selected pages that provided access to TV series and films and were in the general and subject-specific rankings of websites with the most hits in Spain (provided by Alexa.com, Similarweb.com, or SenRush.com).

- Second, we looked at general search engine results for the name of content (titles of TV series and episodes).

- Third, we drew from similar sites that emerged in ranking pages.

- Finally, we used Google's transparency pages, which show requests sent to Google by content owners (and the reporting organizations that act as their representatives) to eliminate links that infringe on copyright legislation.

From the web pages that we identified we selected those that accounted for more than $0.1 \%$ of the total traffic in Spain, according to the information taken from Alexa.com on the data collection days. For each of these pages we 
extracted -from data provided on Alexa.com as part of its subscription service - the percentage of visits that the page received out of the total number of pages visited on the Internet, and the percentage of traffic from Spain. Although this procedure is approximate, it enabled us to quantify the level of access to these websites as an absolute value, compared to the total number of pages visited, and in relative terms to show the relevance of one page within the ecosystem compared to the entire set (Aguilar-Paredes; PérezMontoro, 2015).

In formal terms, for each page $p$ selected, the calculation was made using the following formula:

$$
\text { (a) } \operatorname{Vps}(\%)=\operatorname{Vtp}(\%) \cdot \operatorname{Asp}(\%)
$$

(Where Vps (\%) is the percentage of visits to page $p$ originating in Spain out of the total Internet traffic; Vtp (\%) is the percentage of visits to page $p$ out of the total Internet traffic; and Asp (\%) is the percentage of visits to page $p$ originating in Spain.)

In contrast to the other studies described above, the proposed data collection method enabled us to overcome the issue of extrapolating results drawn from biased samples, and the difficulty in defining specific behavior using small traffic samples. We did not work exclusively with data from notable users (biased samples) or with small Internet traffic samples, but rather with all the statistical data from the overall sample of users, provided by Alexa.com.

We used three waves of data to determine the impact of the measures. The first was studied to discover the relative importance of each website in the ecosystem for accessing TV series and films, and to chart distribution of the different types of access provided just before enforcement of Trlpi. The second and third waves of data collection revealed how visits to the selected sites evolved over a period of three months and one year. This helped to establish whether the set of measures adopted was effective in its intention to reduce this kind of consumer behavior in the short and medium term. The information also provided a full picture of the evolution of the system over a one-year period.

\subsection{Study of the legal services}

In order to quantify the evolution of legal content providers we used data from three sources: that of the main Spanish legitimate OTT servers; data provided by the Spanish $\mathrm{Na}$ tional Markets and Competition Commission (CNMC) of the number of subscribers to pay-TV services in 2015; and the number of plays on the largest (until the arrival of Netflix) VoD content provider in Spain, Yomvi.

\section{Legal over-the-top services}

To measure the traffic of the main legitimate Spanish OTT catch-up TV, transactional catch-up TV, and VoD services offering films and TV series ${ }^{3}$, we employed the same methodology as was used for the pirated-content providers. While there are some 183 on-demand services accessible in Spain (Mavise, 2016), consumption of authorized content on the Internet is limited. RTVE, Telecinco, and Atresmedia offer in-house TV series and films as well as some produced by others, either in open access (including catch-up TV) or by pay-TV through their websites and/or the webpages of their groups (Mitele. es and Atresplayer.com, for free or transactional catch-up TV). Although only a small number of visitors to Telecinco.es and Rtve.es also access the content under study, we show all of the pages visited as our method cannot distinguish access to different content. Nevertheless, using the same methodology (and time lapses) employed to measure the piracy link websites we were able to study the main video on demand (VoD and SVoD) operators that distribute purchased content: Netflix, Yomvi (which was part of Canal+) 4 , Wuaki, Filmin, Nubeox, TotalChannel, Filmotech, and CineClick (though we were unable to assess access to TV series and films on Google Play or iTunes using this methodology). The criterion used to select these services was that they should have a number of visits equivalent to one of the top 200 sites that offer access to illegal content.

Our strategy focuses on analyzing the evolution of access with origin in Spain to such sites throughout 2015

\section{Pay-TV in Spain}

The introduction of pay-TV and VoD services by telecommunications operators in Spain opened up a new way for users to gain access to legal content. These subscription services have registered significant growth since 2010, coinciding with the installation of fiber-optic cables and offers of tripleand quadruple-play services made by the operators. Subscriber details must be given to the regulator (CNMC), which thus provides us with a reliable and up-to-date source for this data (CNMC, 2016).

\section{Yomvi video plays}

Finally, despite the fact that video on demand services of operators in Spain are being audited by Rentrak, only data relating to Yomvi has been made public on a regular basis. We use the monthly VoD report published by Rentrak ${ }^{5}$, which audits the number of plays of a video, in the figure relating to Yomvi (FormulaTV, 2016) to contrast the evolution of plays with the data obtained in the previous step.

The amalgamation of data collected from these three sources allows us to compose a global view of legal service providers and understand their evolution within the studies time frame. The information obtained regarding the two segments of the ecosystem (legal and illegal) provides the tool for understanding the interaction between legal and illegal access to content in Spain.

\section{Results and discussion}

We have divided this section into two parts: an examination of data on legally infringing websites from the first wave of collection and comparison of this with the second and third waves, and discussion about the evolution of legality during the same time frame. 


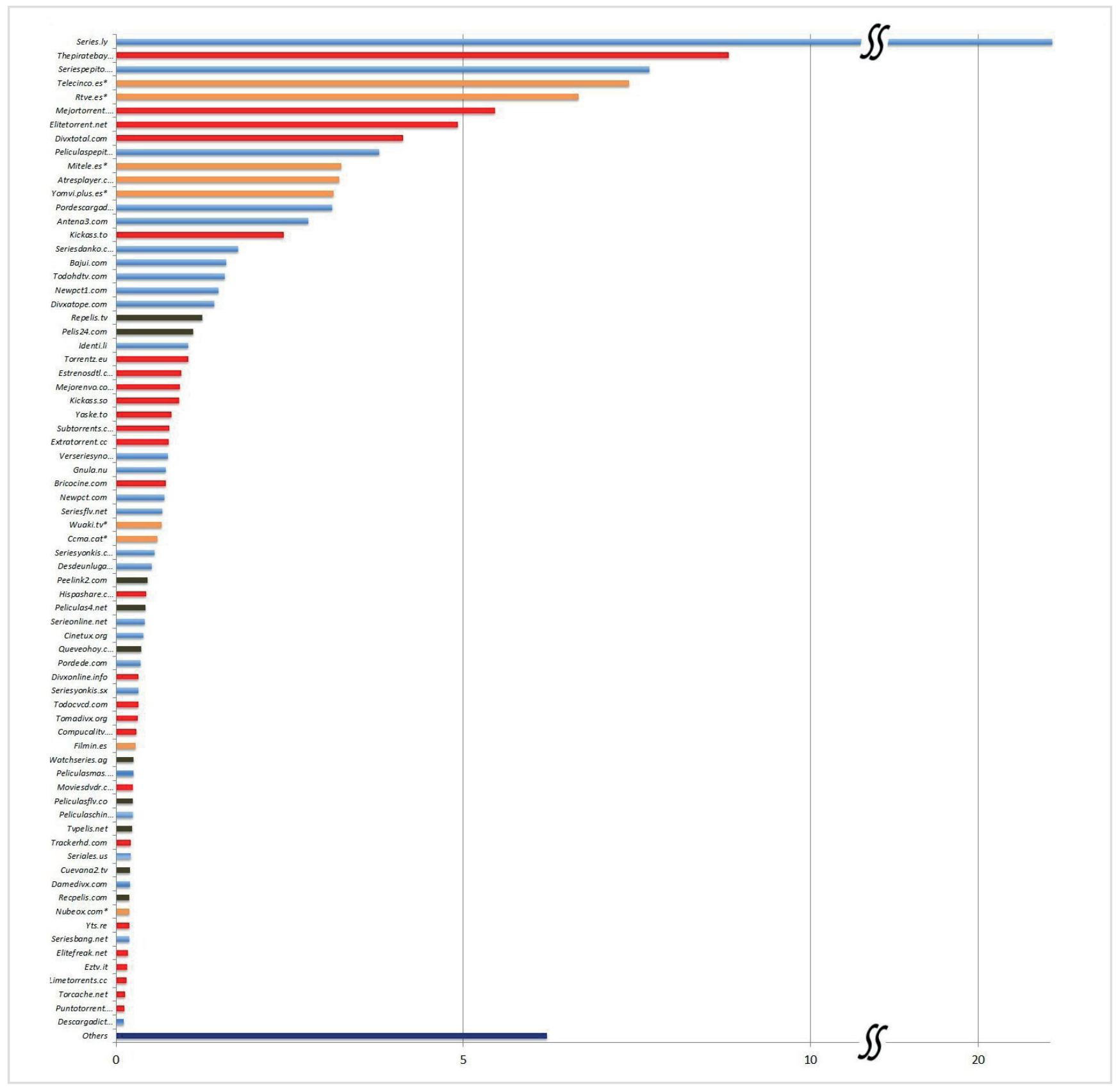

Figure 1. Ecosystem for accessing TV series and films in Spain via websites (data gathered in December 2014)

\subsection{Evolution of the pirate services}

\section{First wave}

As part of the initial search stage, the first wave of data collection was carried out on December 5, 2014, two days after the Seriespepito.com and Peliculaspepito.com (SP) websites were shut down by court order, and three days before Thepiratebay.se (TPB) was taken down. Though these sites had already been blocked, Alexa.com data is provided with a time lag and consequently this wave of data collection corresponds to the last few days that they were available.

In the first wave of collection we identified 201 websites that offered links to legally infringing content and 12 that provided links to licensed material. This enabled us to chart the ecosystem for accessing TV series and films in Spain through webpages, as shown in Figure 1.
The aim was to chart the entire ecosystem of websites offering links to pirated content, but as it was (is) impossible to obtain all of the data, the figure does not include every single site from which such access is possible. Nevertheless, the method enabled us to gather general data on the behavior of those commonly used in Spain to reach over $95 \%$ of audiovisual material, and provided a sample of the rest of the ecosystem.

The chart obtained with the first set of data allowed us to quantify the relative importance of various agents in the ecosystem before the first of the actions that destabilized it-the shutting down of Seriespepito.com. When we analyzed this initial situation, we could see that Series.ly stood out above all the other websites, accounting for a total of $21 \%$ of all the pages accessed. Moreover, some $50 \%$ of all pages visited were part of just six websites (Series.ly, Seriespepito. com, Elitetorrent.net, Thepiratebay.se, Mejortorrent.com, 
and Divxtotal.com). In addition, $80 \%$ of visits were divided among the top 25 websites in the ranking. We should point out that this is a polarized universe, dominated by a small group of sites. Only $10 \%$ of the access to the content was made through webpages below position 50 in the ranking. Consequently, the impact of potential omissions on the total calculation is minimal.

Content was mainly accessed through services hosting files for downloading (54\%) or streaming from the website containing the content (46\%) (in blue in Figure 1), or through pages that carried links to content distributed through P2P networks (mainly BitTorrent sites, in red in Figure 1), which represented $44 \%$ of the total. Some pages provided different access options and were therefore included twice. Legal websites are shown in orange.

A total of $14 \%$ of the pages allowed users to view content embedded in their website (in green in Figure 1). A minority of pages in the ecosystem used this option. It was however the main option in the sites that were accessed less frequently.

\section{Second wave}

The second wave of data collection, conducted on March 5, led to the incorporation of $\mathbf{3 0}$ new names into the ecosystem. Some of these appeared as clones of websites that had been affected by legal action (Seriespepito.to, for example). Others were incorporated as a result of two factors: a change in Google's search filters to block links to sites providing unauthorized access to content (Google, 2014), which meant that less frequently used sites (such as Bricocine.com) could appear and their ranking boosted; and an increase in traffic on websites that were less prominent in the first wave of data collection (Seriesflv.net) as a result of the taking down or marginalization by the search engine of the main providers of links.

So those websites that had not been included in the first wave were integrated into the list. Their traffic figures were extrapolated to the first batch of data gathered using the value obtained in the second wave and the average variation over the last three months provided by Alexa. com. Upon completion of the second wave of data collection we obtained a list of 211 web pages that provided access to illegal audiovisual content.

The enforcement of the Trlpi led to voluntary removal by Series.ly of all of its links to legally infringing content (Series.ly) and announcement of the voluntary shutdown of Elitetorrent.net. In addition, SP and TPB were closed by court order in the first fortnight of December 2014. At the beginning of that month these websites

Figure 2. Changes in types of access together made up a total of $45 \%$ of all links to content in Spain.

However, according to Alexa data, the number of sites visited that provided access to legally infringing content went up by $10.8 \%$ in the three months under study. Figure 3 shows how traffic in the second wave (middle bars in the figure) was no longer dominated by one main actor (as had been the case with Series.(y), but was divided among a large number of sites whose importance in the ecosystem had increased due to an overall rise in the number of visits received and an increase in traffic from Spanish consumers.

\section{We used three waves of data to determi- ne the impact of the measures}

The results of the second wave of data collection show that $50 \%$ of visits were to nine websites (Mejortorrent.com, Elitetorrent.net, Kickass.so, Seriesflv.net, Divxtotal.com, Pelis24. com, Seriesdanko.com, Pordede.com, and Repelis.tv), which accounted for between $8.2 \%$ and $3.7 \%$ of the total traffic. $80 \%$ of all access to content was made through 32 sites, and $95 \%$ through 78 .

There was a higher number of visits to sites that provided access to P2P links, which accounted for $60 \%$ of those visited. A similar trend was observed when Megaupload was taken down (Farahbakhsh et al., 2013). In addition, the number of visits to sites that provided embedded video increased to $35 \%$. Those that provided links to direct downloads and video streaming suffered the largest drop, which was probably due to the closure of SP and removal of links from Series.ly (Figure 2).

\section{Third wave}

The third wave of data collection was carried out in December 2015, one year after the first ${ }^{6}$. During the nine months that had elapsed since the second wave, the acti-

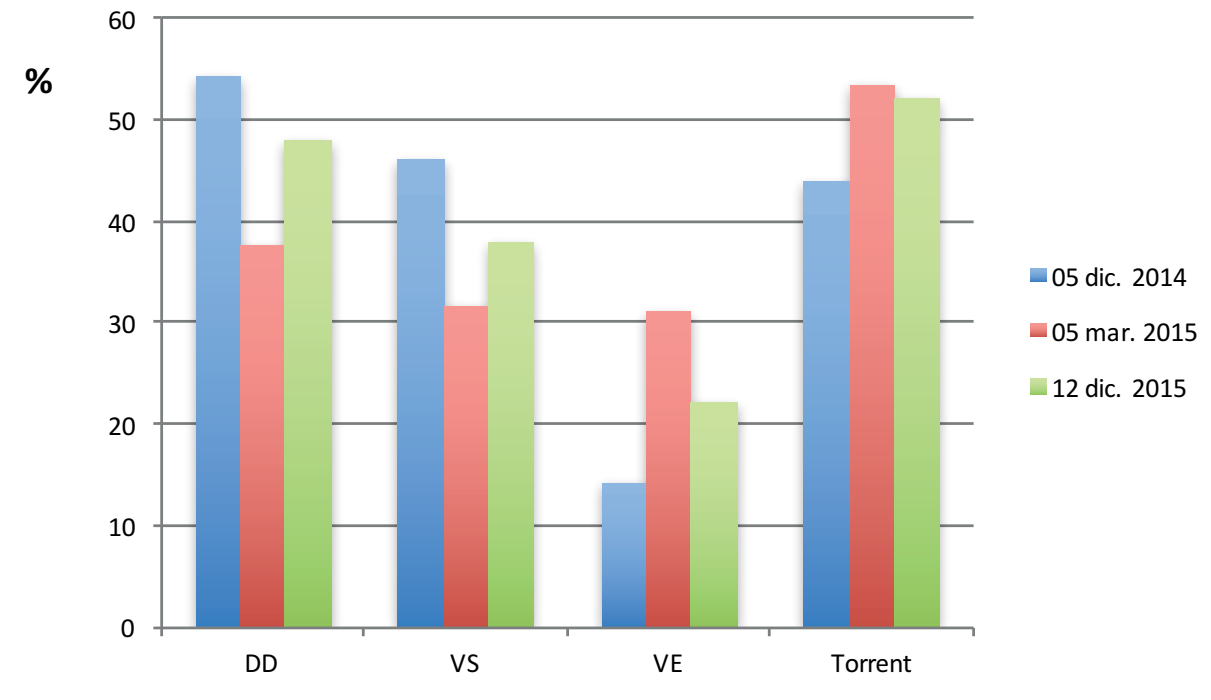




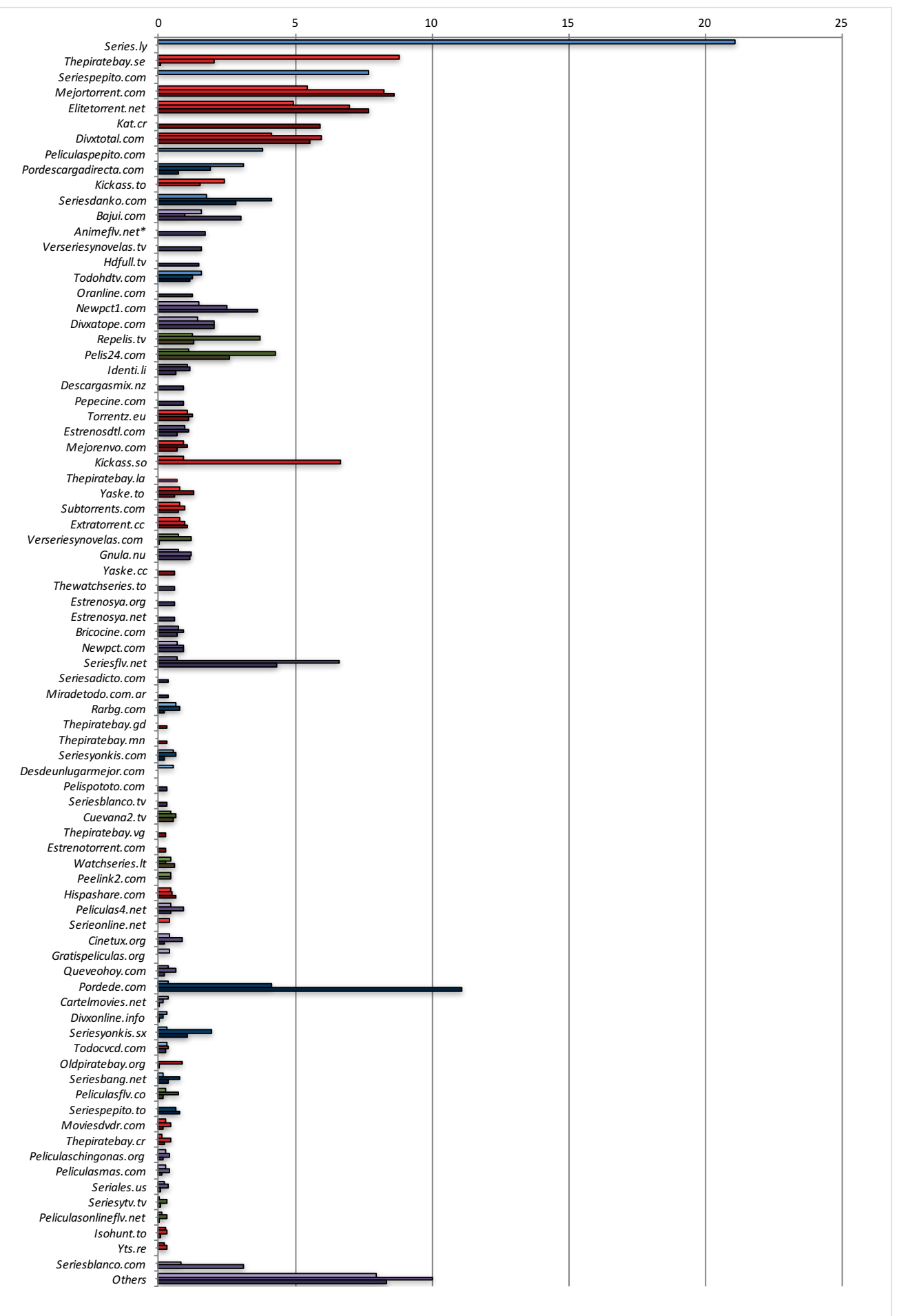

Figure 3. Evolution of traffic on websites containing links (the upper bar for each site corresponds to data collected on 5/12/2014 and the lower bars to that collected on 5/3/2015 and 12/12/2015; blue represents download links/ streaming videos; red corresponds to links to P2P, green to embedded video and violet to various options).

The results of the third wave of data collection show a high concentration of traffic in only eight websites, which accumulate 50\% of visits (Pordede.com, Mejortorrent.com, Elitetorrent.net, Kat.cr, Divxtotal.com, Seriesflv. net, Newpct1.com, and Seriesblanco.com), and which account for between $11.0 \%$ and $3.1 \%$ of the total traffic. Eighty\% of accessed content was made through 32 pages, and $95 \%$ through 89 pages.

No changes were observed in the total amount of traffic. A few increased since the first sample (5\%) and a few decreased since the second wave (5\%). Overall, the number of websites that provided more than one kind of access to illegal content did not changed.

It is almost impossible for this article to determine the choices made by users who had access to the same website to direct download (DD) and video streaming (VS) links, but the growth in use of embedded video (VE) websites in the second wave, and the return in the third wave to DD and VS sites indicated that users tended to use pages that allowed direct access to the content (as if they were VoD services) and use

vity of 67 of the 211 websites monitored had diminished considerably or to levels below the study threshold. This meant the loss of $24 \%$ of accessed pages. However, 108 new websites were added to the study, most of them (Kat. cr, Yaske.cc, or the TPB Hydra) clones of pages that had been shut down. Others (Pepecine.com, Descargasmix.nz, Oranline.com) were new, and a few were accessed more often from Spain than had been reported for the second wave of results. the download options as a refuge when direct access to content was not allowed. The number of visits to sites that provided embedded video fell to $21 \%$ in the third wave, while pages that offered links to direct downloads and video streaming returned to the situation prior to the Trlpi, and Torrent sites were still the most visited (Figure 2). The year 2015 saw Pordede.com consolidated as the most popular link provider (11\% of illegal traffic), taking over for Series.ly in the ecosystem. 


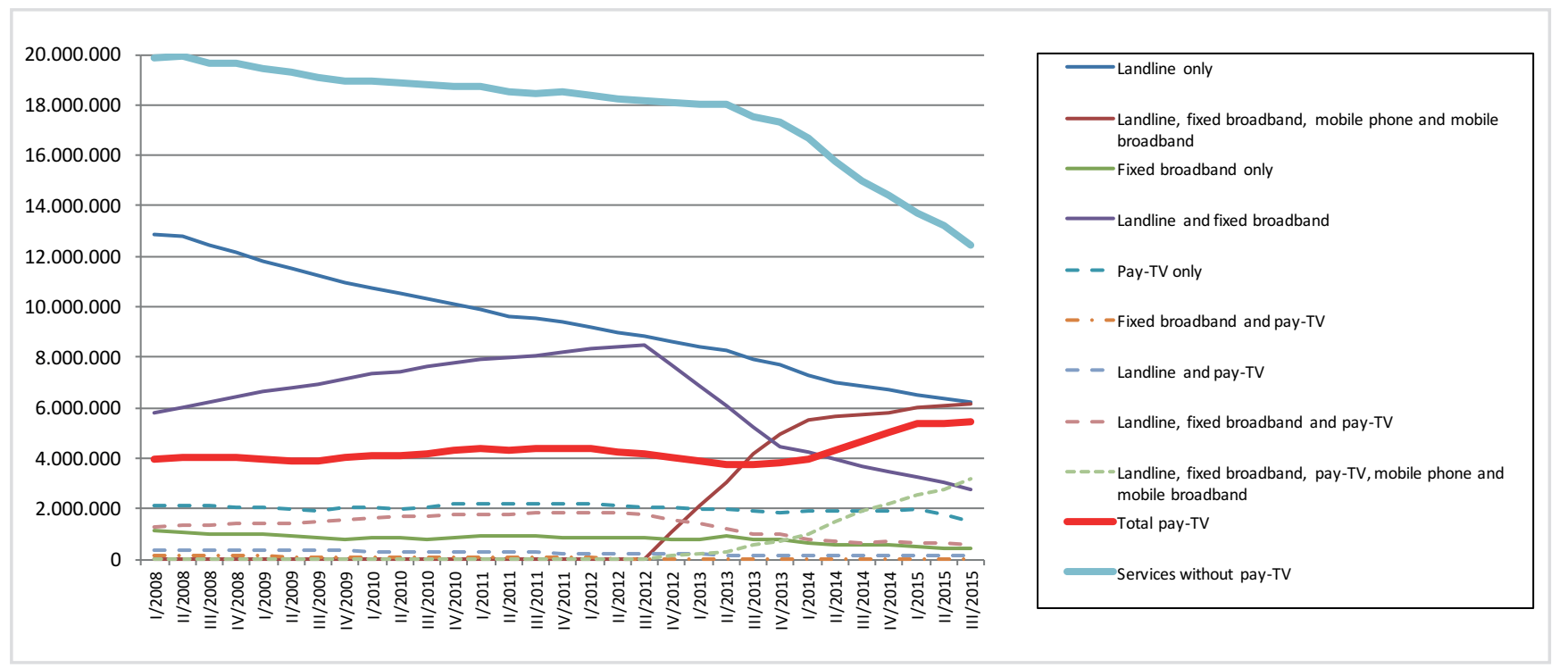

Figure 4. Evolution of pay-TV subscriptions (Data: CNMC)

\subsection{Evolution of legal services}

Websites that offer general content in open access such as catch-up TV (Telecinco.es, Rtve.es, and Antena3.com) were at the same level as the top linked pages in the first wave of data collection. Though we could not distinguish between access to different content or to other pages on the website, open access pages that offered a TV channel's own productions (Mitele.es and Atresplayer.com) had a number of page visits equivalent to the top five linked websites. In 2015 the total traffic to these catch-up services fell by $25 \%$ due the poorer results registered by Telecinco and Mitele.es.

Among OTT services, in 2015 SVoD operators (without counting Netflix) experienced an $89 \%$ increase in traffic from Spain. This data should be understood in the context of that year's far-reaching reorganization of Spanish telecommunications service providers, which included Vodafone's acquisition of ONO, Jazztel's takeover by Orange and the purcha- se of Canal+ by Movistar, finally approved by the Spanish competition watchdog (CNMC, 2015a). This restructuring completely recomposed the map of operators and, thus, the offering of web-accessible pay-TV and VoD services.

\section{National measures exclusively did not} reduce the level of illegal traffic

Of these, Totalchannel.com was the subscription service that grew most in percentage terms in 2015, recording an increase of no less than $450 \%$. The origin of this growth is unrelated to the content that concerns this study (TV series and films) ${ }^{7}$. In contrast, Nubeox.com, the Atresmedia Group's operator, ceased to exist as a service in July 2015, with the services it provided being transferred to Atresplayer Premium, which may explain the performance of this site being the opposite of that registered by the other catch-up TV services.

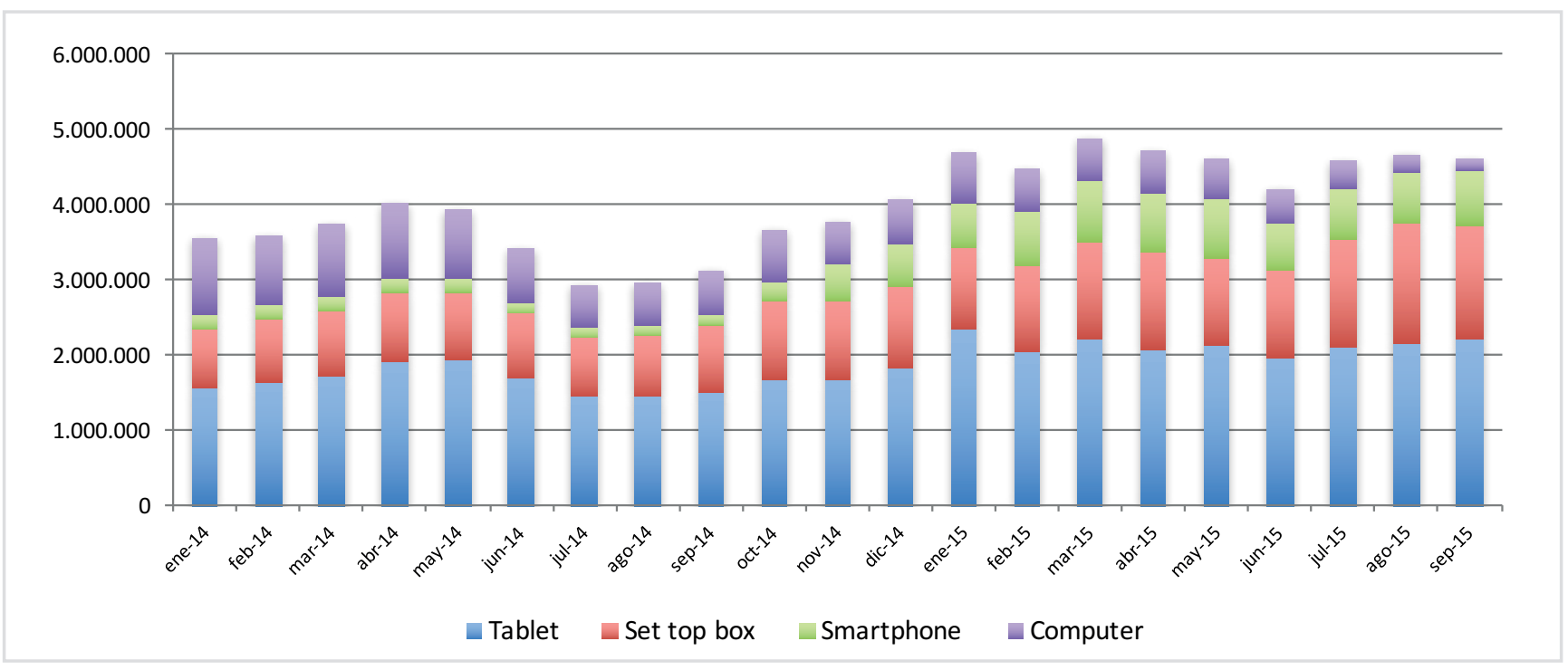

Figure 5. Evolution of Yomvi monthly plays (Data: Rentrak) 
This study also coincided in time with the launch of Netflix in Spain, through both pay-TV and SVoD services. In the third wave of data gathering, Spain contributed only $0.9 \%$ of the traffic to Netflix (via the web). For the Spanish market however, traffic to the Netflix website represented $47 \%$ of VoD operator traffic, exceeding that of Yomvi.

Legal pay-TV saw a huge increase in users during the time interval studied. The data for subscription pay-TV services (red line in Figure 4) increased by 1.3 million users (35\%) in the 01/2014 - 09/2015 period (CNMC, 2016).

As may be observed in Figure 4, the increased contracting of pay-TV services during the study period cannot be dissociated from the tendency evident as from the first quarter of 2014 for customers with double-play contracts (landline and Internet) to transfer to one of the triple- or quadrupleplay options that includes access to pay-TV and associated VoD services.

Finally, evolution of the monthly play data over the same period for Yomvi, the biggest provider of SVoD in Spain before Netflix (Figure 5) shows a $37 \%$ increase in the number of plays during the 01/2014 - 09/2015 period, and a clear tendency towards the use of tablets and smartphones as screens for content consumption (Formula TV, 2016).

\section{The implementation of measures to take down websites that provide access to illegal content has not changed the ove- rall ecosystem of these sites}

The number of plays for Yomvi does not include data subsequent to September 2015, as the takeover of Canal+ by Movistar+ and the change in packages available to Canal+ subscribers resulted in more than three million users having access to Yomvi content. In this new context the data published by Movistar+ show some 40 million plays were produced in November.

Overall, services providing access to legal content have undergone a substantial change in terms of offer, due to both the reconfiguration of operators and the introduction of new content-access services. The data obtained for the three types of paid access services as a whole indicated an increase in their consumption, although this is the continuation of the trend being detected since 2014, and in global terms no variation in this movement can be appreciated as a result of enforcement of the Trlpi.

\section{Conclusions}

The results lead us to conclude that the implementation of measures to take down websites that provide access to illegal content has not changed the overall ecosystem of these sites. Their initial effect however was to bring about greater dispersion of the webs visited in Spain, and an increase in the number of visited sites that provide P2P links or embedded video (Figure 2). In no case did the measures lead to a reduction in access to infringing content or to fewer pages providing this kind of material. Nor did they result in the eradication of sites that operate as de facto SVoD services, given that Pordede.com has now taken the place occupied by Series.ly.

Consequently, the exclusively national measures did not reduce the initial level of illegal traffic. According to data on hosting locations, the websites that originally supported this traffic (PorDescargaDirecta, DivxTotal, EstrenosDTL, DivxATop, Newpct1.com, Elitetorrent.com, Pordede.com) have transferred their servers to other countries not affected by the Spanish legal measures, in a strategy aimed at continuing with their business model.

Users have also modified their behavior in line with alternative consumption methods and the example set by the website managers who chose to rehouse their servers outside Spain. This enables us to confirm the deep-rooted social entrenchment of illegal content consumption. It also leads us to conclude that as a whole the practice has become established as if it were a free access operator and adapted accordingly to the consumption expectations of each user.

Thus the findings of this study are internationally relevant in regards to the penalization by Spanish legislation of links to infringing content. The situation we describe could be considered a model of the future behavior of the download ecosystem which is likely to arise in other countries that decide to enact laws punishing websites providing access to unauthorized material.

Although most members of the academic community believe that anti-piracy laws lead to an increase in the revenue of legal content providers (Danaher; Smith; Telang, 2013), over the study period we observed a $13 \%$ drop in the total number of visits to the 12 legal sites we included. The results found for SVoD operators however (Netflix, Yomvi, Wuaki, Filmin, Nubeox, TotalChannel, Filmotech and CineClick) were consistent with the above statement, registering a $205 \%$ rise in page visits. This was mostly due to the higher number of visits made to Yomvi as a consequence of the growth in triple- and quadruple-play services, and the launch of Netflix in Spain.

Nevertheless, the percentage of traffic on these legal sites was still low. Until now the main sources of Internet traffic have been the American SVoD and film providers: Netflix 34.70\%; Amazon Video, 2.94\%; Hulu, 2.48\%; and iTunes, $2.62 \%$; with file-sharing traffic at 5.42\% (Sandvine, 2015).

Application of the Trlpi coincided with the introduction phase of VoD services offered by the leading Spanish operators and with significant mergers and acquisitions that have restructured and limited the number companies providing these services. The result has been to concentrate the supply of access to TV series and films, linking it to triple- and quadruple-play packages. Packages which allow, as an added value, access to content via the operators' online platforms, thus undermining the role of such platforms as a stand-alone method of access to content and perpetuating a business model that necessarily includes contracting the operators' pay-TV services.

These results also appear to indicate that there was no direct switch of consumers from the illegal to the legal ecosystem. Many new users accessed the offer of legitimate content, but 
they would generally seem to be cord-nevers ${ }^{8}$. This is consistent with the unrelentingly high level of illegal content consumption in Spain, changes within the sector of telecommunications services providers and campaigns to attract new customers to online pay-TV and VoD services (Figure 4) as a result of their concentration policies.

The simultaneous growth of Spain's pay-TV and SVoD services is a consequence of the late development of its contentaccess market. In America, the cord-cutting process is now reducing the number of pay-TV customers and new consumers seem to prefer OTT services (Ericsson, 2015). In Spain however, pay-TV services are still in the process of implementing their VoD platforms, with the peculiarity that the biggest Spanish SVoD service (Yomvi) now belongs to the biggest pay-TV operator, Movistar. The legal pay-TV providers are therefore fighting on two fronts, one against illegal access to content, and the other in a kind of civil war against their own disruptive actors. These include the operators who seek to preserve their pay-TV market while at the same time occupying that of OTT VoD services.

In any case, we conclude that the modifications contained in the Revised Text of the PLI aimed at reducing piracy have not been shown to be effective. The law's negligible impact on the number of Spanish users who access the ecosystem of websites that offer links to unlicensed content and that ecosystem's return to the position it occupied prior to application of the measures are clear evidence of this. What about its role in improving visibility of the legal content offer and the fostering of new business models? Consolidation of the tendency to concentrate pay-TV in the hands of major operators and the inclusion of new VoD services marketed by these same actors lead us also to conclude that no relationship can be found between implementation of the proposed legal measures and any increase in the contracting of legitimate content access services. Likewise, in no case can a cause-effect relationship be established in regards to the transfer of users from one type of consumption to the other.

\section{Notes}

1. Over-the-top (OTT). In the fields of broadcasting and content delivery, OTT means online delivery of video and audio without the Internet service provider being involved in the control or distribution of the content itself. The traffic is not managed. (Busson; Paris; Simon, 2016) (CNMC, 2015b).

2. $\mathrm{OCH}$ is the acronym for one-click hosting file storage providers, or cyberlockers.

3. According to the EU definition of these services established in the report; On-demand audiovisual markets in the European Union.

4. The CNMC approved purchase of Canalt by Movistart in April 2015, and both VoD platforms were merged in July 2015. (CNMC, 2015a).

5. Rentrak has now been merged with ComScore (ComScore, 2016).

6. The data gathered are shown in Table 1 (Appendix), which shows the percentages for sites accessed in the three waves of data collection, as well as the percentage that each re- presented of the total number in the ecosystem. The table provides values relating to the three waves for the 30 websites with the highest percentage of visits, and data on sites that provided legal access to contents, which are shown in blue in Figure 1.

7. Totalchannel owned the rights to televise Champions League football matches during the 2015/2016 season, contents which were not accessible via Canal+ or Movistar Plus, thus causing the umpteenth dispute among Spanish operators for football transmissions (Mediapro, 2016).

8. Cord nevers are defined as viewers who have never subscribed to a multichannel video service. In general, they are young people that probably never will have a subscription to a cable service.

\section{Acknowledgment}

This work is part of the project Interactive content and creation in multimedia information communication: audiences, design, systems and styles. CSO2012-39518-C04-02 (Mineco/ Feder), Spanish Ministry of Economy and Competitiveness.

\section{References}

Adermon, Adrian; Liang, Che-Yuan (2014). "Piracy and music sales: The effects of an anti-piracy law". Journal of economic behavior \& organization, v. 105, pp. 90-106.

https://papers.ssrn.com/sol3/papers.cfm?abstract_id=1752224 https://doi.org/10.1016/j.jebo.2014.04.026

Aguilar-Paredes, Carlos; Pérez-Montoro, Mario (2015). “Mapa del acceso a series y películas en España". Anuario ThinkEPI, v. 9, pp. 144-146.

https://doi.org/10.3145/thinkepi.2015.34

Alcock, Shane; Nelson, Richard (2012). "Measuring the impact of the Copyright amendment act on New Zealand residential DSL users". In: Proceedings of the 2012 ACM conf on Internet measurement. ACM, pp. 551-558.

https://doi.org/10.1145/2398776.2398833

Antoniades, Demetris; Markatos, Evangelos P.; Dovrolis, Constantine (2009). "One-click hosting services: A file-sharing hideout". In: Proceedings of the $9^{\text {th }}$ ACM Sigcomm conf on Internet measurement. ACM, pp. 223-234.

https://www.ics.forth.gr/_publications/1_click_hosting. imc2009.pdf

https://doi.org/10.1145/1644893.1644920

Busson, Alain; Paris, Thomas; Simon, Jean-Paul (2016). "The European audiovisual industry and the digital single market: Trends, issues and policies". Digiworld economic journal, n. 101, pp. 17-40.

https://goo.gl/jUEfQ6

CNMC (2015a). "Aprobamos la concentración Telefónica/DTS en segunda fase y con compromisos sometidos a vigilancia". CNMC blog. Competencia, telecos, audiovisual, energía, transportes $y+, 23$ abril.

https://blog.cnmc.es/2015/04/23/aprobamos-la-concentraciontelefonicadts-en-segunda-fase-y-con-compromisos-sometidos-avigilancia

CNMC (2015b). Caracterización del uso de algunos servicios 
over the top en España (comunicaciones electrónicas y servicios audiovisuales). Documento de trabajo n. 4.

https://www.cnmc.es/Portals/0/Ficheros/Telecomunicaciones/ Informes/20150130_DOC_OTT_21_11_CC_REVISADO.pdf

CNMC (2016). "Estadística trimestral IV 2015. CNMC Data. http://data.cnmc.es/datagraph/jsp/inf_trim.jsp

ComScore (2016). "ComScore and Rentrak complete merger, creating the new model for a dynamic cross-platform world". Comscore, February 1.

https://www.comscore.com/Insights/Press-Releases/2016/2/ comScore-and-Rentrak-Complete-Merger-Creating-the-NewModel-for-a-Dynamic-CrossPlatform-World

Danaher, Brett; Smith, Michael D. (2014). "Gone in 60 seconds: the impact of the Megaupload shutdown on movie sales". International journal of industrial organization, v. 33, pp. 1-8.

https://papers.ssrn.com/sol3/papers.cfm?abstract_id=2229349 https://doi.org/10.1016/j.ijindorg.2013.12.001

Danaher, Brett; Smith, Michael D.; Telang, Rahul (2013). Piracy and copyright enforcement mechanisms. Working paper $\mathrm{n}$. 19150. National Bureau of Economic Research.

https://doi.org/10.3386/w19150

Ericsson (2015). TV and media 2015. The empowered TV and media consumer's influence.

https://www.ericsson.com/res/docs/2015/consumerlab/ ericsson-consumerlab-tv-media-2015.pdf

España (2014). “Ley 21/2014, de 4 de noviembre, por la que se modifica el texto refundido de la Ley de propiedad intelectual, aprobado por real decreto legislativo 1/1996, de 12 de abril y la Ley $1 / 2000$, de 7 de enero, de enjuiciamiento civil". BOE, n. 268, pp. 90404-90439.

https://www.boe.es/boe/dias/2014/11/05/pdfs/BOE-A-2014-11404. pdf

Farahbakhsh, Reza; Cuevas, Ángel; Cuevas, Rubén; Rejaie, Reza; Kryczka, Michal; González, Roberto; Crespi, Nöel (2013). "Investigating the reaction of BitTorrent content publishers to antipiracy actions". In: 2013 IEEE Thirteenth intl conf on peerto-peer computing (P2P). IEEE, pp. 1-10.

http://mirage.cs.uoregon.edu/pub/antipiracy-IEEE_P2P_v10.pdf https://doi.org/10.1109/P2P.2013.6688699

FormulaTV (2016). “Audiencias video on demand España”. Formulatv.

http://www.formulatv.com/audiencias/vod

García-Dorado, José-Luís; Finamore, Alessandro; Mellia, Marco; Meo, Michala; Munafo, Maurizio (2012). "Characterization of ISP traffic: Trends, user habits and access technology impact". IEEE transactions on network and service management, v. 9, n. 2, pp. 142-155.

https://goo.gl/MyN1QP

https://doi.org/10.1109/TNSM.2012.022412.110184

Gavaldà-Miralles, Arnau; Otto, John S.; Bustamante, Fabián E.; Amaral, Luís A. N.; Duch, Jordi; Guimerà, Roger (2014). "User behavior and change. File-sharers and copyright laws". In: Procs of the $10^{\text {th }}$ ACM Intl conf on emerging networking experiments and technologies. ACM, pp. 319-324.

http://www.aqualab.cs.northwestern.edu/publications/258user-behavior-p2p https://doi.org/10.1145/2674005.2675009

Google (2014). How Google fights piracy.

https://drive.google.com/file/d/OBwxyRPFduTN2NmdYdGdJQnFTeTA/ view?pli=1

Jiménez, Héctor; Martí, Borja; Palao, Iñigo (2014). Observatorio de piratería y hábitos de consumo de contenidos digitales. GFK. http://lacoalicion.es/observatorio-de-la-pirateria/ observatorio-de-la-pirateria-2014

Khattak, Sheharbano; Javed, Mobin; Khayam, Sayed-Ali; Uzmi, Zartash-Afzal; Paxson, Vern (2014). "A look at the consequences of internet censorship through an ISP lens". In: Procs of the 2014 Conf on internet measurement, pp. 271-284.

http://sec.cs.ucl.ac.uk/users/smurdoch/papers/ imc14ispcensor.pdf

https://doi.org/10.1145/2663716.2663750

Marx, Nick (2013). "Storage wars: Clouds, cyberlockers, and media piracy in the digital economy". Journal of e-media studies, v. 3, n. 1.

https://doi.org/10.1349/PS1.1938-6060.A.426

Mavise (2016). "On-demand audiovisual service listing". Mavise. Database on TV and on-demand audiovisual services and companies in Europe.

http://mavise.obs.coe.int/odas?event=listing

Mediapro (2015). "Sólo en beIN Sports se podrá seguir toda la UEFA Champions League".

http://www.mediapro.es/esp/noticias1.php

Poort, Joost; Leenheer, Jorna; Van-der-Ham, Jeroen; Dumitru, Cosmin (2014). "Baywatch: Two approaches to measure the effects of blocking access to The Pirate Bay". Telecommunications policy, v. 38, n. 4, pp. 383-392.

https://papers.ssrn.com/sol3/papers.cfm?abstract_id $=2314297$ http://dx.doi.org/10.1016/j.telpol.2013.12.008

Price, David (2013). Sizing the piracy universe. NetNames. https://www.netnames.com/insights/whitepapers/2016/ sizing-the-piracy-universe

Sandvine (2015). Global internet phenomena. Africa, Middle East, and North America. Sandvine, Intelligent Broadband Networks.

https://www.sandvine.com/downloads/general/globalInternet-phenomena/2015/global-Internet-phenomena-africamiddle-east-and-north-america.pdf

Sanjuàs-Cuxart, Josep; Barlet-Ros, Pere; Solé-Pareta, Josep (2012). "Measurement based analysis of one-click file hosting services". Journal of network and systems management, v. 20, n. 2, pp. 276-301.

http://personals.ac.upc.edu/jsanjuas/papers/httpfs.pdf https://doi.org/10.1007/s10922-011-9202-4

Series.ly (2014) El nuevo modelo de consumo audiovisual en internet.

http://cdn.opensly.com/v3/Informe_seriesly_15.pdf

Zhang, Chao; Dhungel, Prithula; Wu, Di; Ross, Keith W. (2011). "Unravelling the BitTorrent ecosystem". IEEE Transactions on parallel and distributed systems, v. 22, n. 7, pp. 1164-1177. http://doi.ieeecomputersociety.org/10.1109/TPDS.2010.123 


\section{Appendix}

Table 1. Percentages and Alexa ranks for main websites that offer links to infringing content and legal services. Legal websites are marked in blue.

\begin{tabular}{|c|c|c|c|c|c|c|c|c|c|c|c|c|}
\hline \multirow[b]{2}{*}{ Web } & \multicolumn{3}{|c|}{ Alexa rank in Spain } & \multicolumn{3}{|c|}{$\%$ visits from Spain } & \multicolumn{3}{|c|}{$\begin{array}{l}\text { \% pageviews from Spain } \\
\qquad\left(\times 10^{-3}\right)\end{array}$} & \multicolumn{3}{|c|}{$\%$ illegal traffic } \\
\hline & $1^{\text {st }}$ wave & $2^{\text {nd }}$ wave & $3^{\text {rd }}$ wave & $1^{\text {st }}$ wave & $2^{\text {nd }}$ wave & $3^{\text {rd }}$ wave & $1^{\text {st }}$ wave & $2^{\text {nd }}$ wave & $3^{\text {rd }}$ wave & $1^{\text {st }}$ wave & $2^{\text {nd }}$ wave & $3^{\text {rd }}$ wave \\
\hline Series.ly & 24 & -- & -- & 87.3 & -- & -- & 4.247 & -- & 0.000 & 20.66 & -- & -- \\
\hline Mitele.es & 83 & 131 & 132 & 87.8 & 89.6 & 86.80 & 2.004 & 0.823 & 0.663 & 9.75 & 3.65 & 2.94 \\
\hline Telecinco.es & 27 & 45 & 66 & 85.2 & 84.4 & 85.70 & 1.944 & 1.772 & 1.312 & 9.46 & 7.85 & 5.81 \\
\hline Thepiratebay.se & 95 & 200 & -- & 2.3 & 3.0 & -- & 1.778 & 0.458 & -- & 8.65 & 2.03 & -- \\
\hline Seriespepito.com & 76 & -- & -- & 52.3 & -- & -- & 1.549 & -- & -- & 7.53 & -- & -- \\
\hline Rtve.es & 50 & 43 & 47 & 70.8 & 74.5 & 72.70 & 1.342 & 1.577 & 1.467 & 6.53 & 6.99 & 6.50 \\
\hline Mejortorrent.com & 123 & 70 & 64 & 82.9 & 87.9 & 0.85 & 1.101 & 1.858 & 1.841 & 5.36 & 8.23 & 8.16 \\
\hline Elitetorrent.net & 82 & 95 & 69 & 85.8 & 95.1 & 0.89 & 1.447 & 1.577 & 1.659 & 7.04 & 6.98 & 7.35 \\
\hline Divxtotal.com & 151 & 110 & 106 & 91.7 & 93.1 & 0.90 & 0.834 & 1.343 & 1.201 & 4.06 & 5.95 & 5.32 \\
\hline Atresplayer.com & 105 & 90 & 113 & 81.4 & 84.7 & 89.40 & 0.810 & 0.916 & 1.073 & 3.94 & 4.06 & 4.75 \\
\hline Peliculaspepito.com & 165 & -- & -- & 69.7 & -- & -- & 0.765 & -- & -- & 3.72 & -- & -- \\
\hline Antena3.com & 91 & 101 & 155 & 76.8 & 83.5 & 81.50 & 0.707 & 0.533 & 0.557 & 3.44 & 2.36 & 2.47 \\
\hline Pordescargadirecta.com & 583 & 675 & 818 & 73.6 & 89.1 & 0.86 & 0.628 & 0.426 & 0.153 & 3.05 & 1.89 & -- \\
\hline Pordede.com & 1,944 & 127 & 76 & 94.1 & 93.4 & 0.89 & 0.070 & 0.927 & 2.397 & 0.34 & 4.11 & 10.62 \\
\hline Netflix.com* & -- & -- & 81 & -- & -- & 0.9 & -- & -- & 1.435 & & -- & 6.35 \\
\hline Plus.es & 195 & 174 & 90 & 91.7 & 92.6 & 96.50 & 0.599 & 0.776 & 1.278 & 2.91 & 3.44 & 5.66 \\
\hline Kickass.to & 841 & 185 & -- & 0.8 & 1.4 & -- & 0.486 & 0.338 & -- & 2.36 & 1.50 & -- \\
\hline Kat.cr & -- & & 131 & -- & -- & 0.02 & -- & -- & & -- & -- & \\
\hline Seriesdanko.com & 775 & 229 & 399 & 77.4 & 78 & 0.74 & 0.355 & 0.930 & 0.609 & 1.73 & 4.12 & 2.70 \\
\hline Bajui.com & 645 & 831 & 537 & 73.8 & 89.7 & 0.84 & 0.319 & 0.212 & 0.650 & 1.55 & 0.94 & 2.88 \\
\hline Todohdtv.com & 802 & 798 & 1,526 & 73.1 & 88.6 & 0.86 & 0.316 & 0.280 & 0.248 & 1.54 & 1.24 & 1.10 \\
\hline Newpct1.com & 497 & 285 & 196 & 86.8 & 94 & 0.93 & 0.297 & 0.562 & 0.783 & 1.44 & 2.49 & 3.47 \\
\hline Divxatope.com & 465 & 324 & 371 & 86.9 & 93.4 & 0.93 & 0.285 & 0.461 & 0.442 & 1.39 & 2.04 & 1.96 \\
\hline Repelis.tv & 390 & 305 & 452 & 13.7 & 32 & 0.13 & 0.251 & 0.842 & 0.282 & 1.22 & 3.73 & 1.25 \\
\hline Pelis24.com & 515 & 143 & 201 & 15.3 & 39.1 & 0.23 & 0.225 & 0.964 & 0.561 & 1.09 & 4.27 & 2.49 \\
\hline Identi.li & 596 & 581 & 1,069 & 14.6 & 24.3 & 0.12 & 0.210 & 0.257 & 0.135 & 1.02 & 1.14 & 0.60 \\
\hline Torrentz.eu & 816 & 516 & 489 & 0.8 & 1.1 & 0.02 & 0.210 & 0.282 & 0.238 & 1.02 & 1.25 & 1.05 \\
\hline Estrenosdtl.com & 469 & 453 & 612 & 93.9 & 97.3 & 0.93 & 0.190 & 0.250 & 0.147 & 0.92 & 1.11 & 0.65 \\
\hline Mejorenvo.com & 890 & 653 & 997 & 41.5 & 52.1 & 0.39 & 0.184 & 0.241 & 0.143 & 0.90 & 1.07 & 0.63 \\
\hline Kickass.so & 336 & 446 & -- & 1 & 1.6 & 0.04 & 0.184 & 1.501 & 0.000 & 0.89 & 6.65 & 0.00 \\
\hline Yaske.to & 869 & 670 & -- & 9.6 & 20.4 & -- & 0.160 & 0.289 & -- & 0.78 & 1.28 & -- \\
\hline Yaske.cc & -- & -- & 868 & -- & -- & 15.00 & -- & -- & 0.130 & -- & -- & \\
\hline Subtorrents.com & 1,077 & 815 & 1,070 & 37.1 & 46.9 & 0.34 & 0.155 & 0.219 & 0.160 & 0.76 & 0.97 & 0.71 \\
\hline Extratorrent.cc & 1,742 & 1,164 & 1,172 & 0.6 & 0.8 & 0.01 & 0.154 & 0.221 & 0.232 & 0.75 & 0.98 & 1.03 \\
\hline Verseriesynovelas.com & 806 & 622 & 38,241 & 16.7 & 35.5 & 0.16 & 0.150 & 0.268 & 0.003 & 0.73 & 1.19 & 0.01 \\
\hline Verseriesynovelas.tv & -- & -- & 528 & -- & -- & 0.17 & -- & -- & 0.341 & & & 1.51 \\
\hline Gnula.nu & 871 & 481 & 450 & 23.4 & 38.1 & 0.22 & 0.145 & 0.264 & 0.247 & 0.71 & 1.17 & 1.09 \\
\hline Seriesflv.net & 857 & 111 & 169 & 13.5 & 51.1 & 0.31 & 0.135 & 1.494 & 0.932 & 0.66 & 6.62 & 4.13 \\
\hline Wuaki.tv & 840 & 937 & 645 & 67.80 & 59.8 & 0.70 & 0.130 & 0.163 & 0.173 & 0.62 & 0.72 & 0.77 \\
\hline Seriesyonkis.sx & 2,858 & 484 & 1,175 & 36.8 & 71.8 & 0.74 & 0.065 & 0.441 & 0.223 & 0.32 & 1.95 & 0.99 \\
\hline Filmin.es & 1,599 & 1,799 & 1,126 & 73.2 & 84.7 & 76.90 & 0.059 & 0.079 & 0.118 & 0.29 & 0.35 & 0.52 \\
\hline Nubeox.com & 3,477 & 2,655 & -- & 81.9 & 70.9 & -- & 0.047 & 0.062 & -- & 0.23 & 0.28 & -- \\
\hline Totalchannel.com & 20,883 & 5,794 & 5,495 & 91.2 & 93.2 & 94.50 & 0.006 & 0.018 & 0.035 & 0.03 & 0.08 & 0.15 \\
\hline Filmotech.com & 29,414 & 38,775 & 46,500 & 59.6 & 46.7 & 51.50 & 0.005 & 0.000 & 0.001 & 0.02 & 0.00 & 0.01 \\
\hline Cineclick.com & 49,004 & 18,013 & 29,968 & 52.0 & 57.3 & 53.20 & 0.003 & 0.004 & 0.001 & 0.01 & 0.02 & 0.01 \\
\hline
\end{tabular}


$7^{a}$ Conferencia internacional sobre revistas

de ciencias sociales y humanidades

CRECS 2017

Cuenca, 4-5 mayo

\section{httpil/crecs.info}

El profesional de la

Anusano
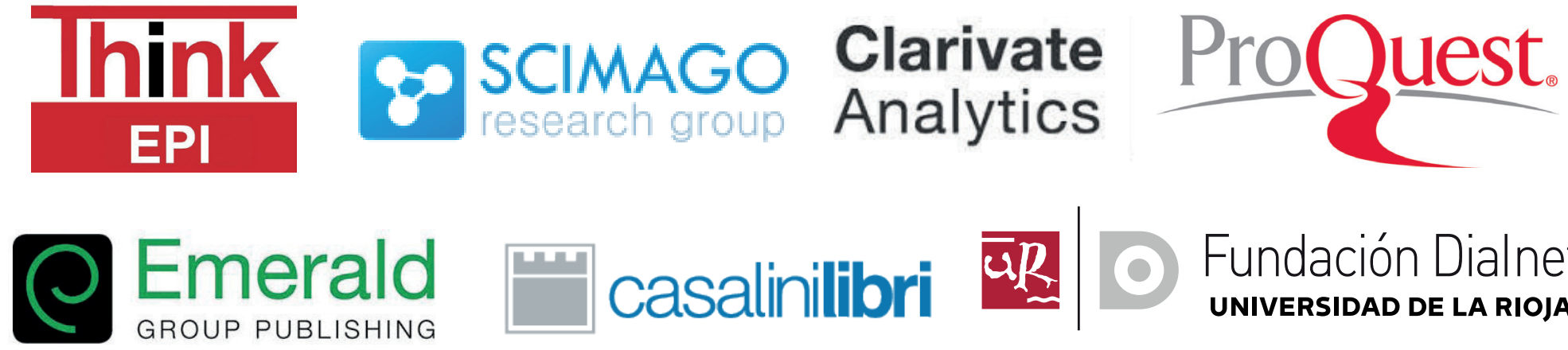

casalinilibri 鵙

SPRINGER NATURE EEZ3metrics。

EBSCO
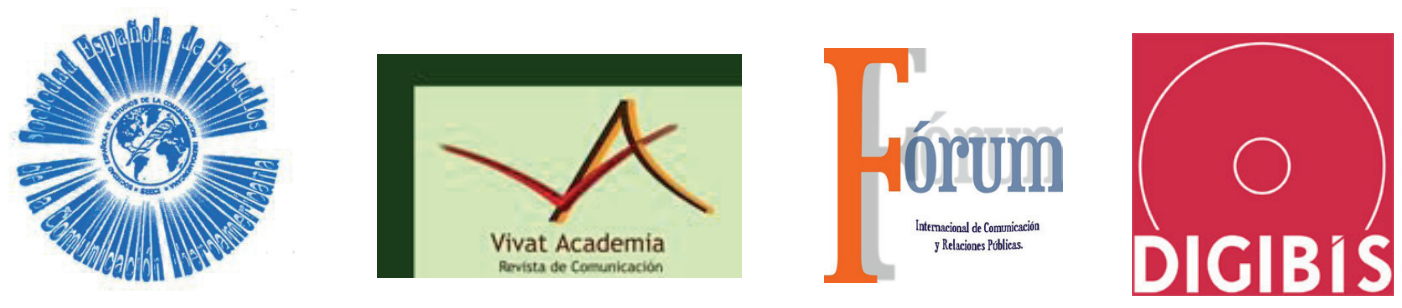